\title{
Neurogenic muscle atrophy in myasthenia gravis
}

\author{
BETTY BROWNELL ${ }^{1}$, D. R. OPPENHEIMER, AND J. M. K. SPALDING \\ From the Departments of Neuropathology and Clinical Neurology, United Oxford Hospitals, Oxford
}

SUMMARY Two cases of severe myasthenia gravis are described, with histological findings. Both cases showed severe neurogenic atrophy of the muscles of the tongue, with fatty pseudohypertrophy and a remarkable proliferation of terminal nerve fibres. Similar, but less severe, changes were present in other bulbar muscles. The findings are in keeping with the view that functional interruption at the neuromuscular junctions results first in failure to transmit the contractile impulse, and at a later stage in denervation atrophy. Terminal proliferation of axons is regarded as an attempt, on the part of motor fibres, to compensate for the breakdown of normal neuromuscular interaction.

Until fairly recently, it was thought that myasthenia gravis had no characteristic histopathological features other than scattered 'lymphorrhages' in skeletal muscle. Russell (1953) described various 'myopathic' and inflammatory changes in myasthenic muscles, including myocardium. Coërs and Desmedt (1958), Bickerstaff and Woolf (1960), and MacDermot (1960) described abnormalities in the terminations of motor nerve fibres as shown by methylene blue techniques, and their findings have been confirmed by subsequent workers. Substantial neurogenic muscular atrophy is not a generally recognized feature of the disease, although minor degrees of neurogenic atrophy have occasionally been reported (Fenichel and Shy, 1963; Brody and Engel, 1964; Hughes and Brownell, 1968). There are no known abnormalities in the central nervous system or in the cell bodies and axons of the motor neurones.

This paper concerns two cases of myasthenia gravis, with severe involvement of the bulbar musculature. In both of them, the tongue enlarged and became intractably weak, making partial amputation necessary. In both cases the histology of the tongue showed severe muscle atrophy, with fatty replacement. The atrophy was of neurogenic type, but the atrophic fascicles contained abundant nerve fibres. These appearances, we believe, have not been described before.

1 Present address: The Burden Neuropathological Laboratory, Frenchay Hospital, Bristol.

\section{CASE 1}

W.L., a farmer, developed ptosis at the age of 40 years. It was worst at the end of the day, was more severe on the right than the left, and responded to edrophonium. A diagnosis of myasthenia gravis was made. He was helped at first by neostigmine, but within two months he had developed dysphagia, drooping of the jaw and widespread weakness of myasthenic type, which included respiratory muscles. Thymectomy and tracheostomy were performed. He was given artificial ventilation and was fed by a nasogastric tube. In the subsequent seven years his condition has fluctuated considerably. At his best he can drive a tractor, at his worst he cannot breathe spontaneously or turn over in bed. At first he was usually able to swallow soft food, but about four years after the onset he required a gastrostomy because of recurrent and prolonged periods of difficulty in swallowing. Five years after the onset his facial appearance was such that he refused to be seen in public because his jaw hung open and his tongue was large, paralysed and protruding. Plastic surgery improved this with a bilateral facial sling and removal of a substantial part of the tongue. He has repeatedly received courses of ACTH 800-1200 units in about 10 days, with or without withdrawal of anticholinesterases. He becomes weaker during this time, and improves subsequently, probably above his previous level. The dose of neostigmine which gives him most strength varies between $1.25 \mathrm{mg}$ and $2.5 \mathrm{mg}$ by intramuscular injection every three hours. With each dose he usually takes atropine $0.6 \mathrm{mg}$ by intramuscular injection.

Electromyography of the ulnar-supplied muscles of the right hand was normal when the patient presented and had only ophthalmoplegia. Five years 
after the onset, however, he showed the typical changes of myasthenia gravis in the small muscles of the right hand. There was no spontaneous activity. Maximum voluntary effort evoked a moderate number of single motor units, some of which were polyphasic and of long duration. Recordings from the right orbicularis oculi, right levator labii superioris, and right orbicularis oris muscles showed no activity at rest or in response either to maximum voluntary effort or maximum electrical stimulation of the facial nerve. The appearances supported the clinical diagnosis and suggested complete denervation in the right facial musculature and partial denervation in the small muscles of the right hand.

PATHOLOGY 1. Thymus Removed three months after onset. Stripped of surrounding fat, the specimen consisted of a firm, lobulated mass measuring $5 \times 3 \times 1 \mathrm{~cm}$. Microscopically, normal thymus tissue was seen at the margin; the rest of the tissue showed proliferation of small cells of lymphocytic type, with comparatively few epithelial cells. This was regarded as a thymic hyperplasia rather than a true thymoma.

2. Biopsy of omohyoid muscle Removed three months after onset. The muscle, and its innervation as seen in silver impregnations, appeared normal.

3. Distal part of tongue Removed five years after onset. The specimen measured $5 \frac{1}{2} \times 2 \frac{1}{2} \mathrm{~cm}$ at the base, and about $6 \mathrm{~cm}$ from the base to the tip. Posteriorly, the dorsum showed well-marked longitudinal grooves, about $1 \mathrm{~cm}$ from the midline, and anteriorly a deep midline furrow. The cut surface was pale and fatty, and practically devoid of recognizable muscle tissue.

Microscopically, the bulk of the tissue consisted of fat, through which there ran normal-looking $\stackrel{\mathbb{D}}{=}$ vessels and nerve bundles and isolated fascicles of $\underline{0}$ severely atrophied muscle (Fig. 1).

The appearance and the grouping of these atrophic fibres, in routine stains, was indistinguishable from that of neurogenic atrophy. There was no inflammatory reaction, and no sign of necrosis or phagocytosis of muscle fibres, or of fibrous scarring. In the medial and dorsal part of the tongue, between the longi- $\underset{\mathcal{S}}{\mathcal{S}}$ tudinal grooves, there was considerably less fat, and the tissue consisted of interlacing muscle fascicles, some of normal appearance, others showing various $\vec{F}$ degrees of atrophy, affecting small groups rather $\stackrel{\rho}{\rightarrow}$ than scattered individual fibres (Fig. 2).

In silver impregnations, the innervation of the preserved, eutrophic, muscle fibres was seen to be highly abnormal, with excessive branching of termi- $\mathbb{\mathbb { }}$ nal axons, elongated and otherwise malformed $\triangleq$ motor endings, and multiple end-plates on single $\vec{P}$ muscle fibres (Fig. 3). The appearance of the atrophic fascicles was even stranger. Here, there $\vec{\omega}$


was an extravagant profusion of branching and $\exists$ anastomosing nerve fibres, of very varied calibre? (Figs 4 and 5). The axons in the nerve bundles, on the other hand, appeared normal, and there was no sign of loss of nerve fibres. The mucosa, and i innervation, seemed normal; but some of the mucous glands contained compact complex nerê endings, with the histological structure of so-called Krause end-bulbs (Fig. 6). The origin and nature these is not certain, but they have been considered be products of obstructed nerve growth (Oppew heimer, Palmer, and Weddell, 1958).

\section{CASE 2}

V.H., a housewife, died at the age of 52. Ten years before she died the patient had her first symptom

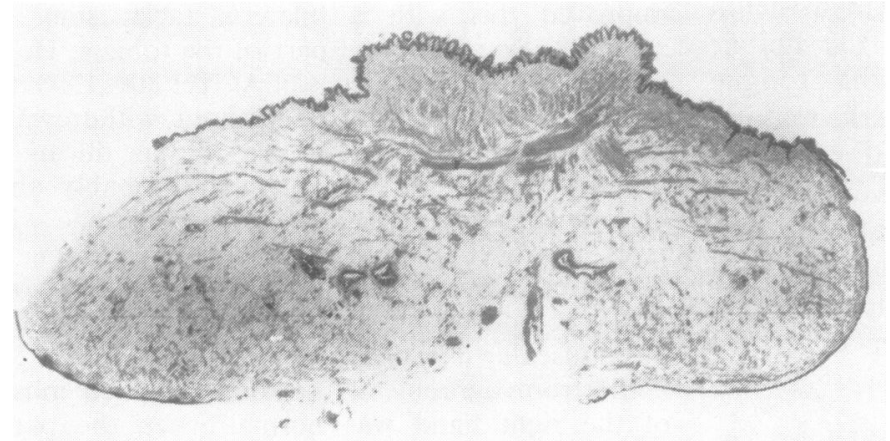

FIG. 1. Case 1. Transverse section of amputated tongue, showing triple furrowing, severe muscle atrophy and $\mathrm{\bigcirc}$ fatty replacement. Relative preservation of muscle in dorsum. $H$ and $E$, $\times 2$. 


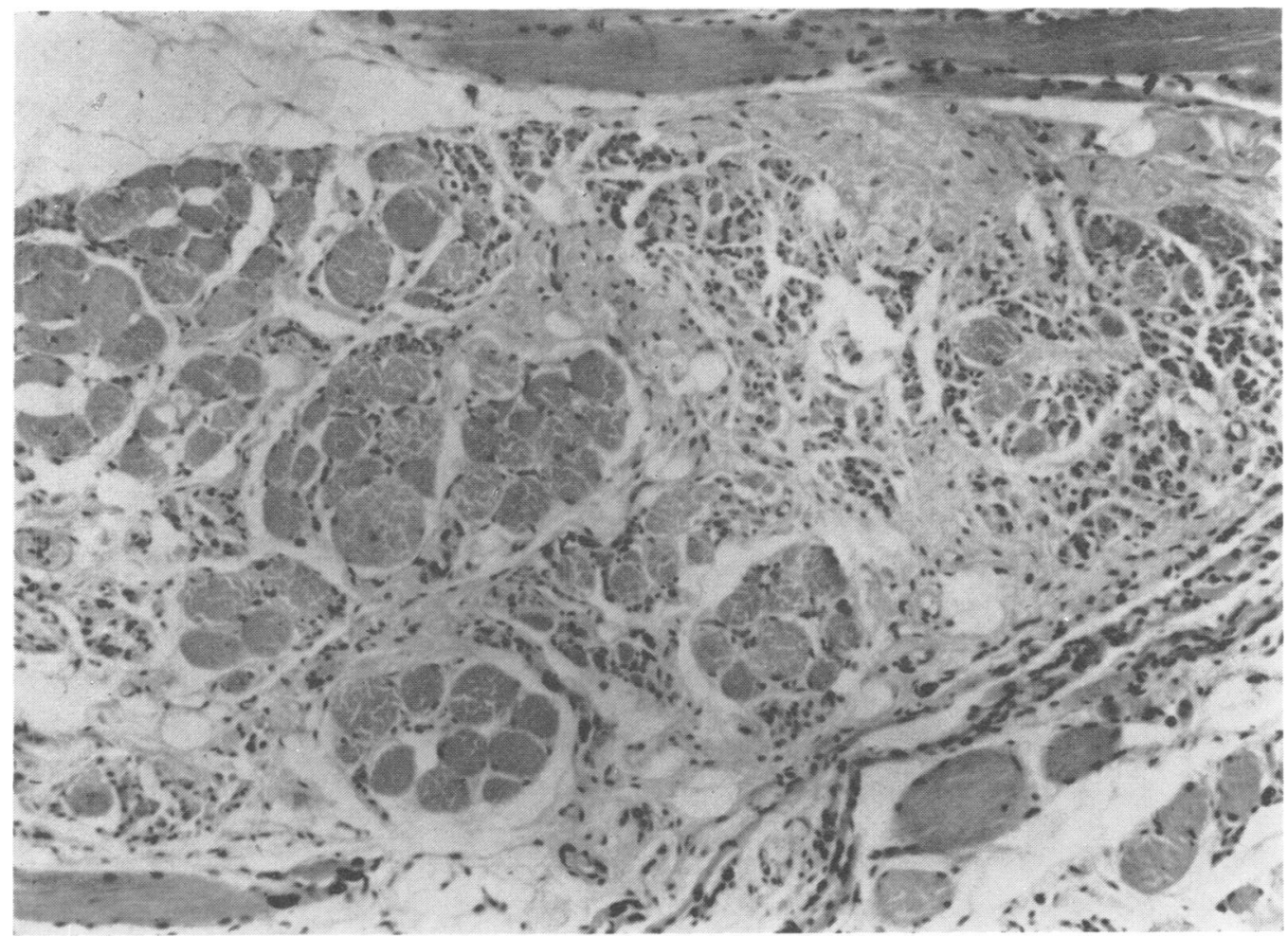

FIG. 2. Case 1. Dorsum of tongue, showing characteristic picture of neurogenic atrophy. $H$ and $E, \times 80$.

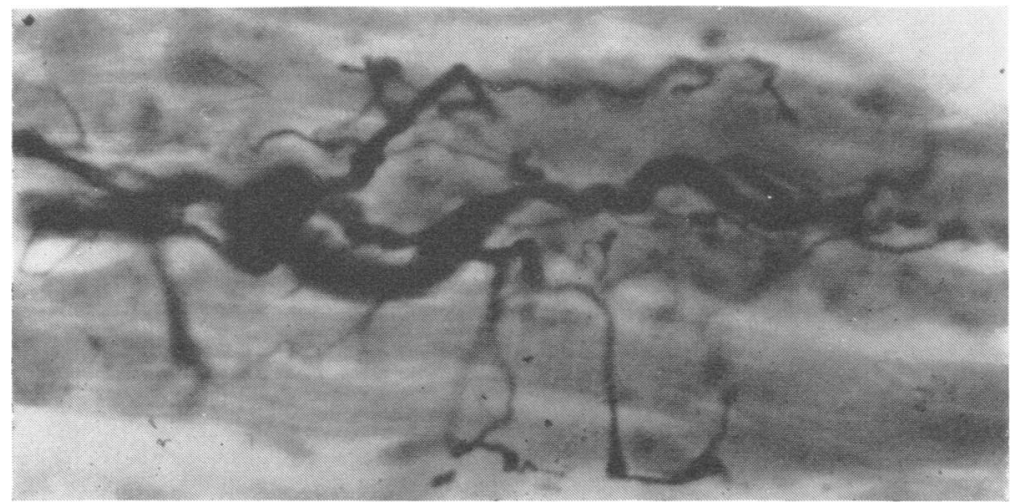

FIG. 3. Case 1. Abnormal terminal axons and motor endings on eutrophic muscle fibres in dorsum of tongue. Schofield, $\times 500$. 


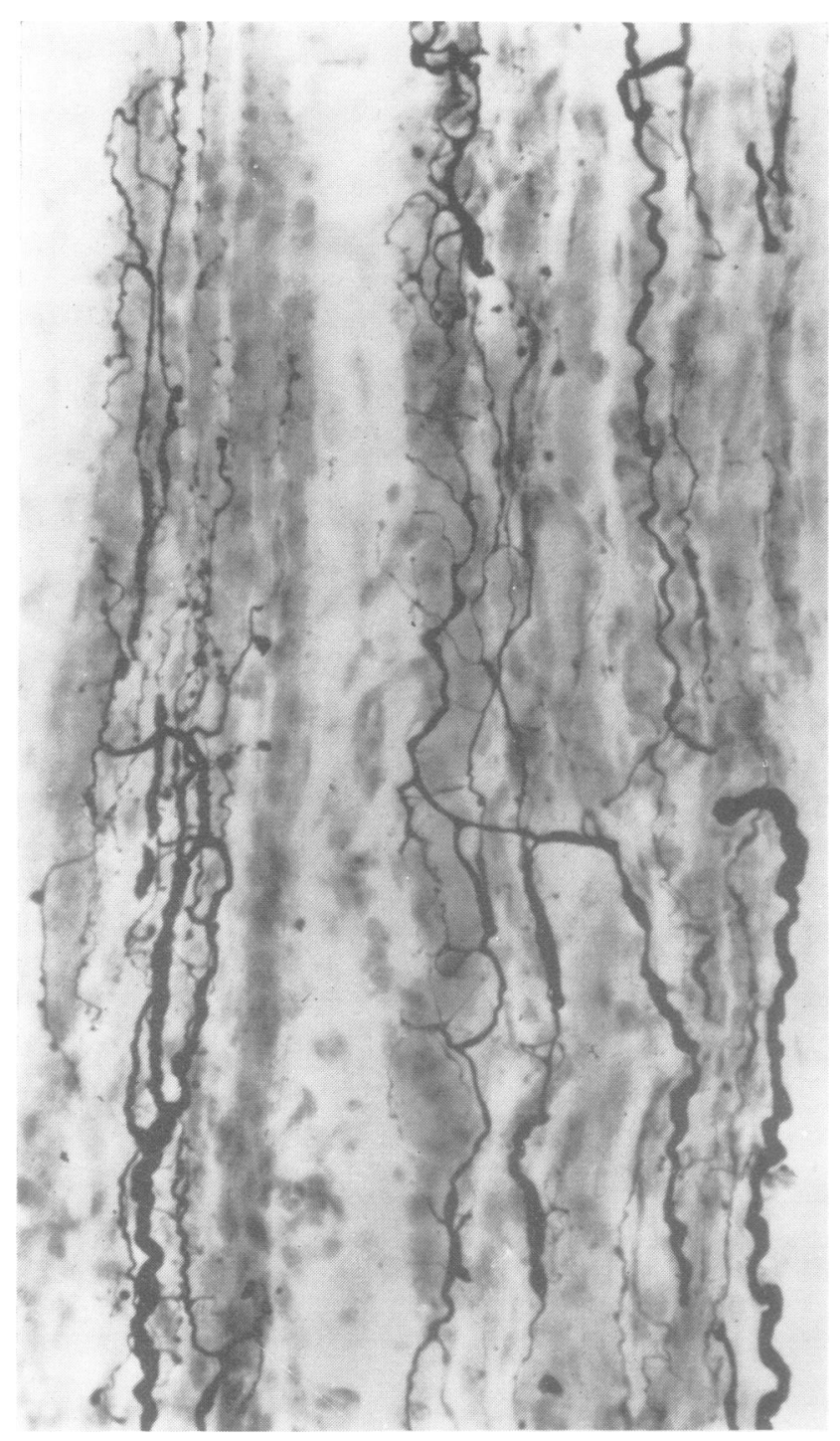

FIG. 4. Case 1. Tongue, showing proliferation of nerve fibres, abnormal branching and formation of numerous lateral and terminal expansions. The muscle fibres are atrophic. Schofield, $\times 200$.

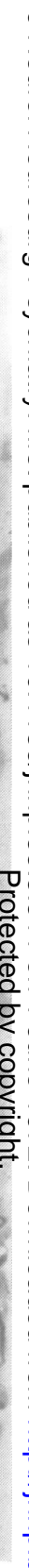

FIG. 5. Case 1. Tortuous, irregularly thickened, branching and anastomosing nerve fibres in atrophic muscle. Schofield, $\times 200$. 


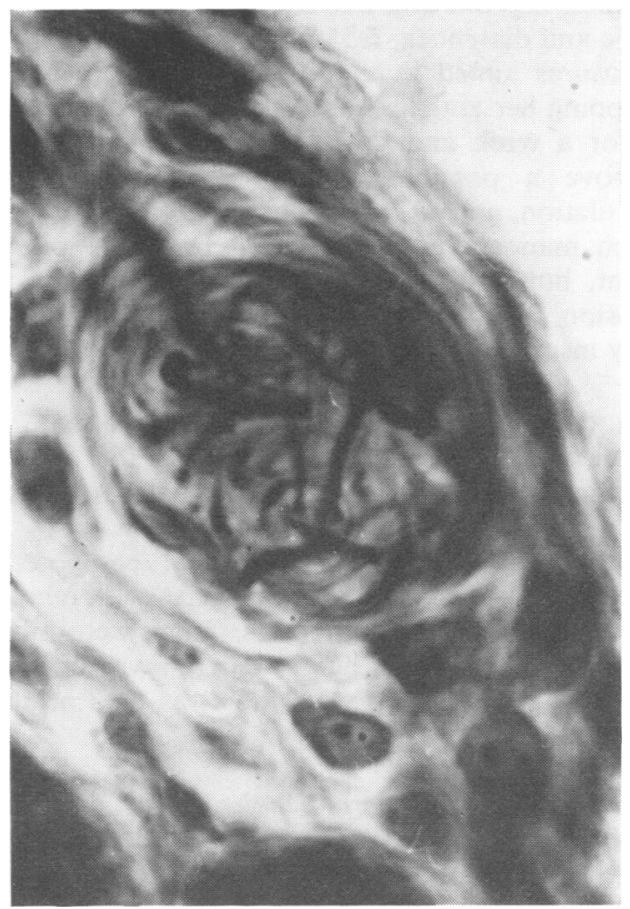

FIG. 6. Case 1. 'End-bulb' alongside salivary gland: a globular encapsulated tangle, supplied by a single nerve fibre. Schofield, $\times 1,000$.

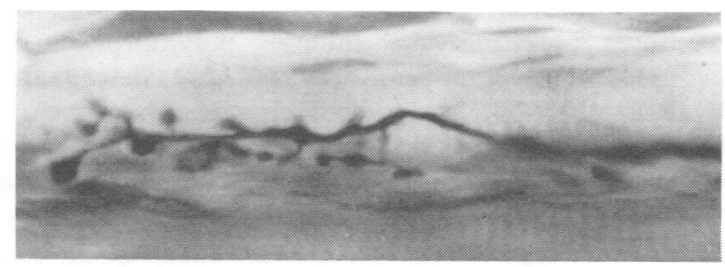

(a)

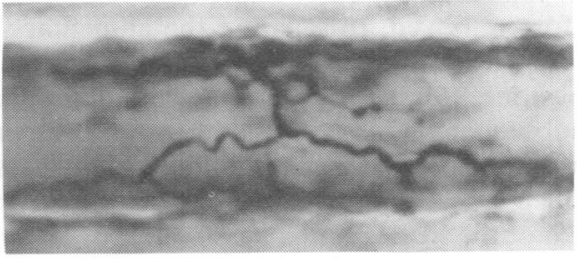

(d)

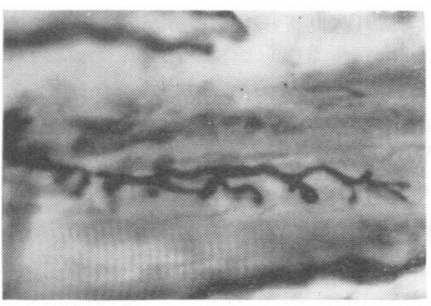

(b)

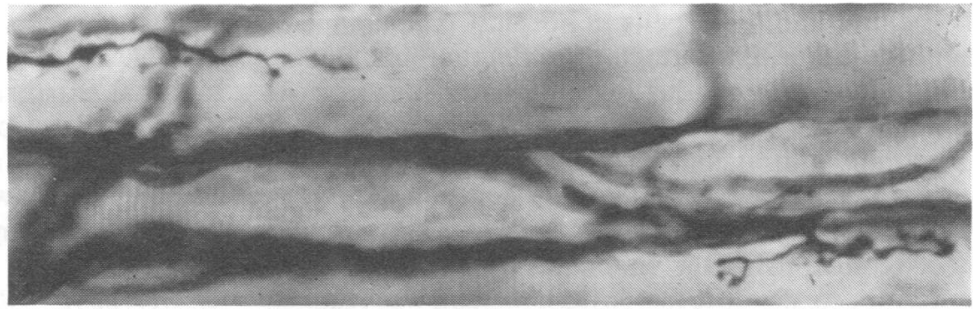

(c)

FIG. 7. Case 2. Laryngeal muscles (a and b, cricothyroid; $\mathrm{c}$ and $\mathrm{d}$, cricoarytenoid) showing abnormally branched and elongated endings on eutrophic muscle fibres. Schofield, a $\times 300 ; \mathrm{b}, \mathrm{c}$, and $\mathrm{d}, \times 200$. 
of myasthenia gravis, inability to chew. Two days later she developed a severe right ptosis, and after a further five days her speech was slurred and her mouth hung open. She was admitted to hospital where, in addition to these abnormalities, fasciculation was seen in the tongue. Facial movements and swallowing were found to be normal. She later developed diplopia. Neostigmine by injection caused complete recovery in speech and relief of ptosis. Thirteen days after her first symptom, while eating, she became cyanosed and semiconscious. She was transferred, with artificial respiration through an endotracheal tube, to the Respiration Unit at the Churchill Hospital. The physical signs were confirmed, including fasciculation of the tongue. Artificial respiration was continued through a tracheostomy for six months, but, although she could then breathe spontaneously, she had serious ptosis and weakness in chewing and swallowing, and to a lesser extent weakness of the limb and trunk muscles. Thymectomy was therefore performed, with the finding of a small thymoma. For some weeks afterwards she remained weak. She then made a good recovery, and on optimum doses of neostigmine she had little or no ptosis, and her limbs were strong enough to allow her to walk short distances and to travel. She did not recover her ability to phonate even when air was artificially blown through the larynx, and she developed a tracheal dilatation at the level of the cuff on the tracheal tube, so that it became difficult to make a good seal. As a result she developed recurrent chest infections. The larynx was therefore removed, to separate the alimentary from the respiratory tract (Smith, Spalding, Ardran, and Livingstone, 1965). Gastrostomy was also done, and she subsequently took part of her nourishment by mouth and part by gastrostomy. Her masseters remained weak, and her tongue protruded from her open mouth, to her embarrassment. Mr. Eric Peet therefore re-modelled her mandible and removed the anterior two-thirds of the tongue, with substantial improvement to her appearance.

During the subsequent years she lived mostly at home, but had long spells in hospital. The course of her illness showed characteristic fluctuations, but on the whole she got gradually weaker over the years. At her worst she was unable to walk, or to give herself injections, and at her best she was able to go on a cruise. The level of anticholinesterase medication was adjusted by varying the dose of intramuscular neostigmine, using the vital capacity as the principal criterion. As the dose increased a plateau was reached where further increases produced no improvement, and she was given the lowest dose which reached this plateau. Latterly this meant neostigmine 3.75 or $5 \mathrm{mg}$ every two hours, day and night, to a total daily dose of $46.25 \mathrm{mg}$. She also had enough atropine to prevent colic and diarrhoea, $5.55 \mathrm{mg}$ a day in divided doses.으 Measures aimed at inducing a remission included $Z$ stopping her anticholinesterase for a week, stoppinge it for a week and giving curare, renal dialysis to remove a possible paralysing substance in the circulation, and ACTH about 1,000 units in 10 days. Each manoeuvre was followed by some improve-0 ment, but none of them produced a dramatic re-⿳亠丷厂 mission. She died at home, apparently from respira-⿳⺈⿴囗十灬 tory insufficiency.

PATHOLOGY 1. Thymus Removed about six months after onset. Stripped of fat, the specimen consisted of an encapsulated, lobulated mass, firm음 and white on section, measuring $5 \times 4 \times 1 \frac{1}{2} \mathrm{~cm}$. Histologically, it was a thymoma, composed of closely packed cells of epithelial type, with relativelyos small numbers of lymphocytes. There were mitoses in moderate numbers, but no sign of invasive spread: A small area of normal thymus was present at the $\vec{\omega}$ margin.

2. Biopsy of $M$. pectoralis major Six months after onset. This appeared normal, both in routine andor silver impregnations, apart from a few interstitgi li aggregations of lymphocytes.

3. Larynx Removed two years after onset. Stern thyroid, cricothyroid, and cricoarytenoid muscesc were examined. Routine staining showed irregular $8 y=$ of fibre size, central nuclei, and isolated necro $c_{-}^{\mathbb{D}}$ fibres, exciting an intense polymorphonuclearre reaction. The appearance was that described Fy? Russell (1953) as a type I change. There were noO 'lymphorrhages', no small basophil fibres, and noß clear evidence of neurogenic atrophy. The main abnormality, seen in silver impregnations, was aD florid overgrowth of nerve terminals (Fig. 7). Thesed terminal fibres, which normally cross the muscle fibres at an oblique angle, to end in one or two compact end-plates, were seen as elongated fibres of irregular calibre, with small lateral excrescences and frequent branchings, running for long distances along: the length of muscle fibres and ending in bizarre terminal expansions. The appearance corresponded ${ }^{0}$ with the descriptions of myasthenic nerve endings given by Coërs and Woolf (1959) and MacDermot. (1960), and to what we have ourselves observed in? biopsies from myasthenic patients.

4. Necropsy (R.I. p.m. no. 943/69). The subject was a thin middle-aged woman, with healthy tracheostomy and gastrostomy openings and surgicals scars over the neck, chest, and abdomen. There was evidence of healed pleurisy on both sides, and the

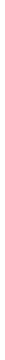


lungs showed areas of collapse. In spite of the previous amputation, the tongue was of approximately normal size. On section, as in case 1, it was largely composed of fat. In the neck, the muscles attached to the hyoid appeared atrophic; there was no obvious muscle wasting elsewhere.

Histologically, the myocardium showed a mild diffuse fibrosis, but no other lesions. The thyroid was of normal size, but abnormal structure. Most of the acini were very small, and contained little or no colloid. The lining cells were large, with very pale cytoplasm. There was no significant degree of lymphocytic infiltration. A colloid adenoma was present on one side. The remaining viscera were unremarkable.

The brain and spinal cord appeared normal, both to naked eye and in their histology. In particular, no changes were seen in the motor cells of the anterior horns, hypoglossal or other cranial motor nuclei. Sections of median, femoral, and popliteal nerves, and of sensory and sympathetic ganglia, also appeared normal.

Muscles from the limbs, and diaphragm, showed

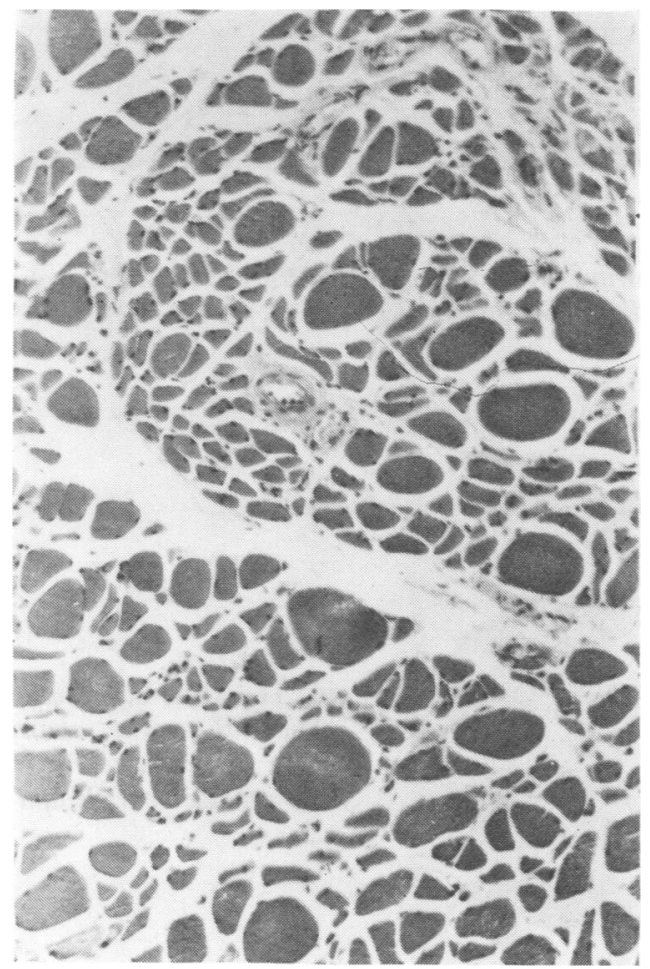

FIG. 8. Case 2. Sternomastoid muscle, showing atrophy of neurogenic type. $H$ and $E, \times 135$. no significant atrophy, but there were a few scattered foci of inflammatory cells, and occasional necrotic muscle fibres undergoing phagocytosis. In silver preparations, the intramuscular nerve bundles and many of the terminal axons and end-feet looked normal, but there were occasional abnormalities of terminal innervation, including excessive branching, multiple innervation of single muscle fibres, and elongation of end-plates with multiple lateral excrescences.

In contrast with the limb muscles, muscles from the neck (sternomastoid and digastric) showed severe changes. There was scattered fibre atrophy, considered to be neurogenic on the basis of preservation of nuclei and cross-striations, shrinkage and angularity, and the formation of small groups of atrophic fibres (Fig. 8). Clear-cut motor unit atrophy was not seen, suggesting a very distal level of denervation. In addition to these changes, myopathic features were present, consisting of necrotic muscle fibres, clusters of inflammatory cells, including polymorphs, and overgrowth of fibrous tissue between and around muscle fibres (Fig. 9).

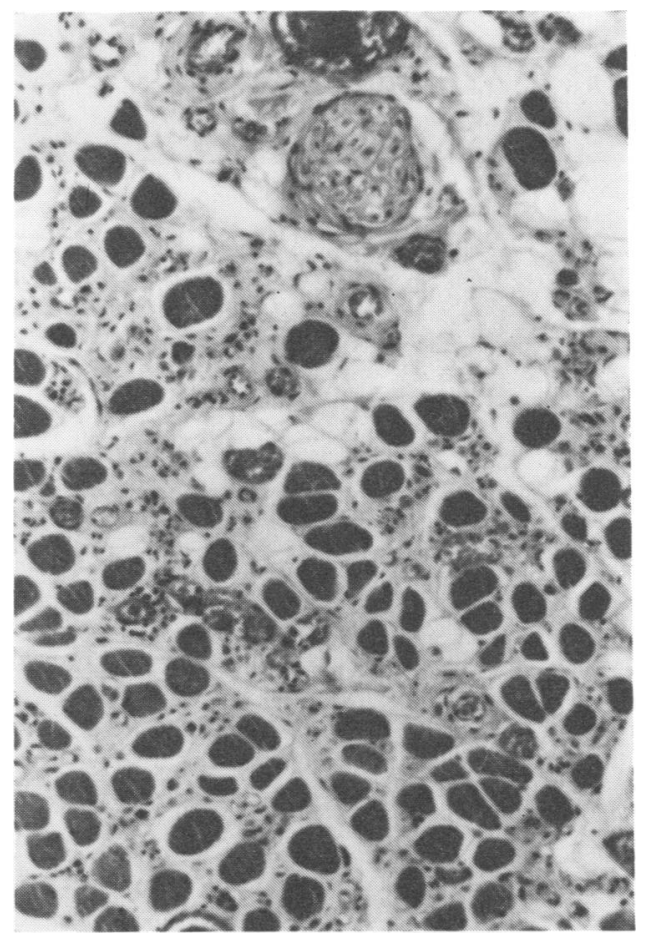

FIG. 9. Case 2. Posterior belly of digastric muscle, showing some necrotic muscle fibres, inflammatory infiltration and interstitial fibrosis. $H$ and $E, \times 135$. 
Nerve bundles in the abnormal muscles appeared normal, but silver preparations showed striking changes, similar to those previously seen in the laryngeal muscles, consisting of abnormal branching of terminal axons, and florid elongated end-feet (Fig. 10). The general effect was of gross overinnervation.

The tongue closely resembled that in case 1 , being composed mainly of fat, interspersed with normallooking vessels and nerves, and isolated fascicles of atrophic muscle (Figs 11 and 12). The atrophic process was more advanced than in case 1 , in that there were no intact fascicles, but merely scattered eutrophic fibres. In addition, there were myopathic changes, similar to those seen in the neck muscles (Fig. 13), including some large aggregations of lymphocytes. Silver impregnations showed numerous nerve fibres of irregular calibre, with abnormal branching, running for long distances along the atrophic muscle fibres (Fig. 14). Recognizable end- plates were seen only in relation to eutrophic fibres.

Florid nerve endings and multiple branchingso were also present in external eye muscles; but as $Z$ these features are commonly present in 'normal' $\stackrel{\mathbb{S}}{\subseteq}$ subjects, they cannot be regarded as significant. The eye muscles contained lymphocytic aggregations, but showed no atrophy.

\section{DISCUSSION}

The histological findings in these two cases can be summarized thus:

1. Abnormal nerve terminations in otherwise normal-looking muscle (case 2). The abnormali- $\overline{\frac{\bar{m}}{7}}$ ties are most striking in the bulbar musculature, $\overrightarrow{\mathbb{Q}}$ and are not associated with 'myopathic' lesions.»

2. Atrophy, of neurogenic type and moderate severity, in the bulbar musculature (case 2).

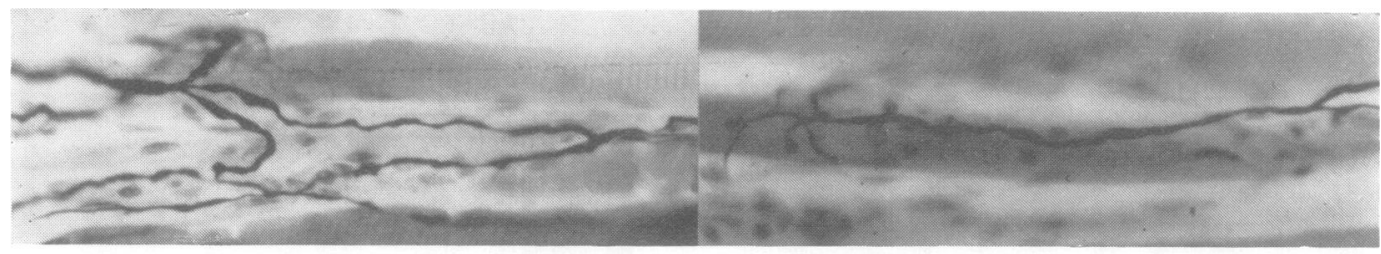

(a)

(b)

FIG. 10. Case 2. Posterior belly of digastric muscle, showing (a) abnormal branching of terminal axons and (b) abnormally elongated endings. Schofield, $\times 200$.

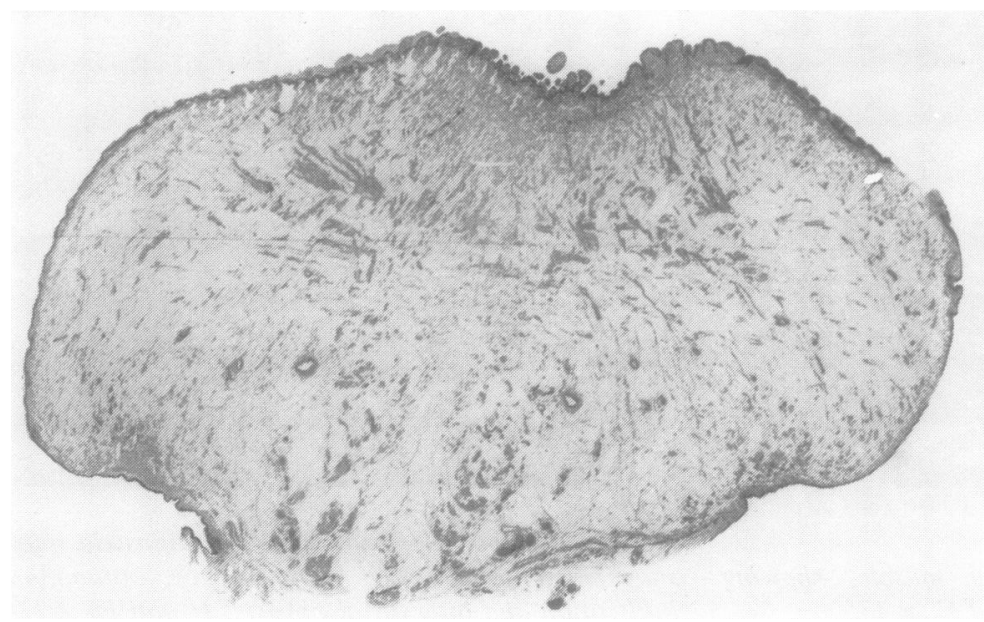

FIG. 11. Case 2. Transverse section of tongue, showing 0 severe muscle atrophy with? fatty replacement. $H$ and $E, \varnothing$ $\times 2$. 


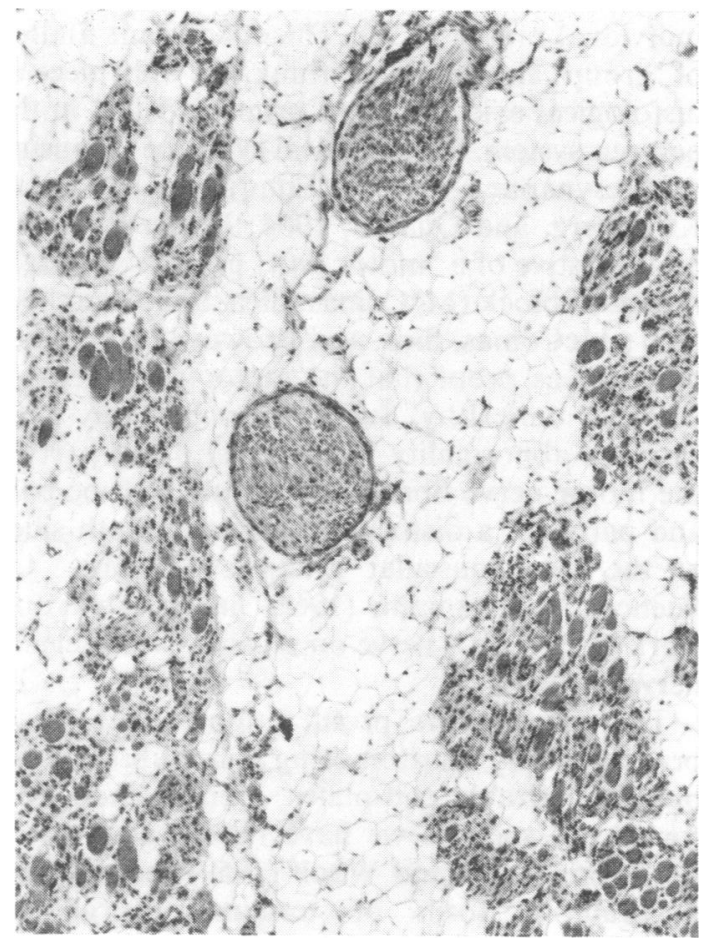

FIG. 12. Case 2. Tongue, showing advanced neurogenic atrophy, with fatty replacement, and normal nerve bundles. $H$ and $E, \times 60$.

3. Very severe atrophy, of neurogenic type, with fatty pseudohypertrophy, in the tongue (cases 1 and 2).

4. Proliferation of nerve terminations, with bizarre branchings and swellings, in the atrophic portions of the tongue.

5. 'Myopathic' lesions in muscle innervated from the brain-stem (case 2).

6. On the negative side, absence of any feature suggestive of loss of motor cells or axons, and normal appearance of motor cell bodies-in particular, those of the hypoglossal nuclei in case 2. Further, there is nothing to suggest that the picture is complicated by a second disease process. Thymic hyperplasia (or, as some would call it, diffuse thymitis) in case 1 , and a thymoma in case 2, must be regarded as normal features of myasthenia gravis.

No simple explanation can be used to account for all these histological features. Taking them in order: the elongated, overelaborate, motor

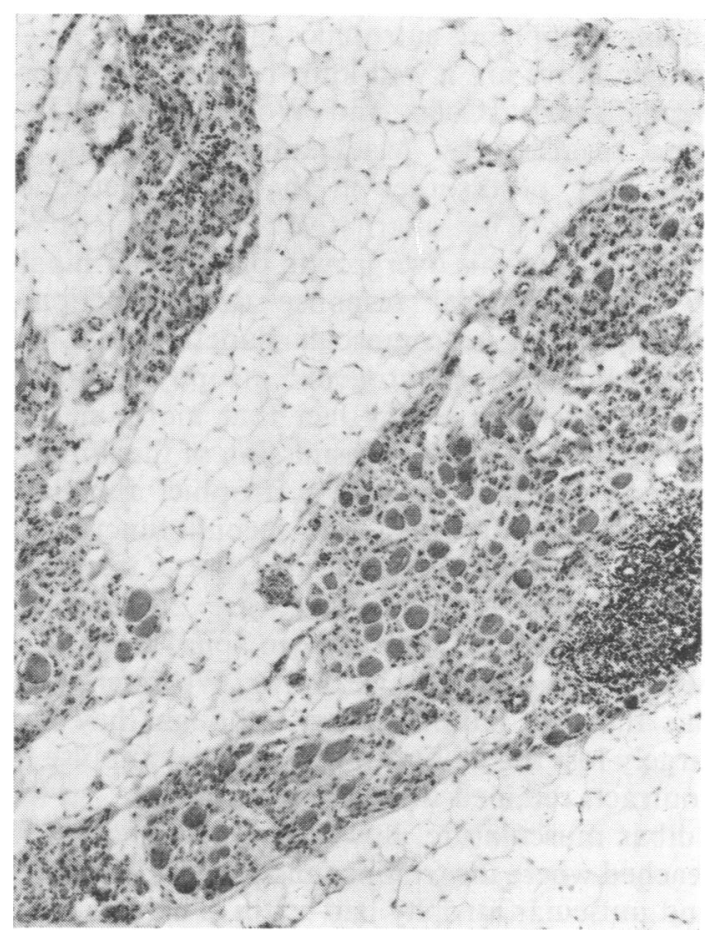

FIG. 13. Case 2. Tongue, showing both atrophy and myopathic features, including a 'lymphorrhage'. $H$ and $E, \times 60$.

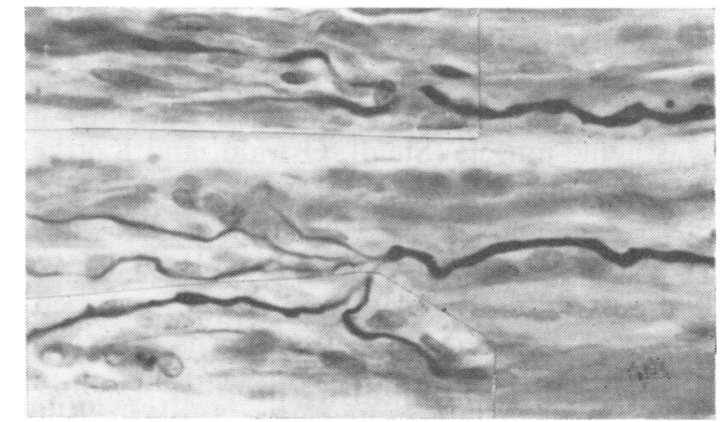

FIG. 14. Case 2. Tongue, showing irregular branching fibres running alongside atrophic muscle fibres. No recognizable motor endings. A eutrophic fibre is seen below. Schofield, $\times 300$. 
endings supplying eutrophic-normal-lookingmuscle fibres are a well-known feature of myasthenia gravis (Coërs and Woolf, 1959). They were regarded by MacDermot (1960) as an indication of disorder in the motor neurones themselves. The alternative view, which we prefer, is that this overgrowth of nerve terminals is a physiological response to a functional inadequacy of neuromuscular junctions.

The finding of 'neurogenic' atrophy of muscle directs attention to the fact that motor nerves have two functions-transmission of the impulse causing contraction, and a 'trophic' function. The manner in which this second function is carried out is still uncertain (see Gutmann, 1964; Guth, 1968). In our case 2, the limb muscles remained eutrophic in spite of a severe neostigmine-resistant weakness. We infer from this that the motor nerves, although they had largely lost the ability to transmit the impulse to contract, retained their trophic influence. In the bulbar musculature, however, a stage had been reached where the trophic function was impaired, and muscular atrophy had set in. This last stage was far advanced in the muscles of the tongue in both our cases.

Visible wasting of the tongue was described by Buzzard in 1905, and again by Wilson (1955), who drew attention to the 'triple furrowing' of the myasthenic tongue. This feature is illustrated by Simpson (1969), and was observed in the amputated specimen in case 1. Russell (1953) examined tongues from myasthenic patients, but neither she nor any other writer known to us has described the changes seen in our two cases. The concomitant fatty pseudohypertrophy, which largely masks the muscular wasting, is also, we believe, a new observation.

In previous reports of neurogenic atrophy in myasthenic muscle (Steidl, Oswald, and Kottke, 1962; Fenichel and Shy, 1963; Brody and Engel, 1964; Fenichel, 1966; Hughes and Brownell, 1968) the affected muscle fibres have shown either a diffusely scattered or a 'grouped' pattern of distribution. Both patterns were seen in our case 2. Since the trophic function of motor nerves, whatever its nature, is presumably exercised in the region of the motor end-plate, these observations imply that failure of this function may affect either scattered, isolated endplates or all or most of the end-plates served by

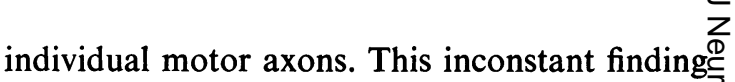
of 'group' atrophy is, we think, the only piece of histological evidence for a primary defect in the ${ }_{\infty}$ nervous system. Physiological evidence favouring a presynaptic defect (Elmqvist, Hofmann, Kugelberg, and Quastel, 1964; Desmedt, 1966), or suggestive of a 'motor unit' pattern of neuromuscular block (McComas, Sica, and Campbell, 1971; McComas, Sica, and Brown, 1971) cannoto. be taken as proof that the motor neurone as a whole is unhealthy. Such evidence merely indi- $\Rightarrow$ cates an abnormality in the most distal part of the motor nerve fibre, which could well be parto and parcel of a disturbance affecting both sides $\frac{\bar{\sigma}}{\overline{0}}$. of the neuromuscular synapse. 'Trophic' in-क्ष fluences, as Gutmann (1964) has pointed out, work both ways - nerve on muscle, or muscle on nerve.

The extravagant proliferation of irregular, $\vec{\omega}$ branching and anastomosing nerve fibres, with-o out recognizable end-plates, seen in these two tongues is such as we have never encountered elsewhere. Coërs and Woolf (1959) describe and illustrate a form of terminal overgrow ('neurocladism') in which there is a disorder\$y $\overrightarrow{ }$ tangle of terminal fibres, with anastomosifgo branches and multiple abnormal end-plates. $\vec{c}$ They regard this as a response of nerve termingtions to certain types of primary muscle fibege degeneration. What we have described diffesis $\overrightarrow{0}$ from this not merely in the degree of corn $N$ plexity, but in the fact that no recognizable end-O plates are present. Here again the question arises whether these bizarre distortions of nerveō terminals are due to a primary disorder of motor\% neurones, or whether they are a physiological $\stackrel{\circ}{2}$ response of healthy neurones to the presence of $\overrightarrow{0}$ diseased muscle fibres. We regard the second 3 alternative as the more likely.

The 'myopathic' changes seen in the bulbar: musculature in case 2 are a recognized feature of myasthenia gravis (Russell, 1953), and may well! be the result of an autoimmune assault on muscle 3 . fibres. A severe myositis has been produced acutely in guinea-pigs injected with extracts of $₹$ bovine thymus (Goldstein, 1968). The author'so illustrations of the lesions show some similarity to lesions seen in human myasthenia and mayo well have a similar pathogenesis. The same animals also developed a partial blockage of neuromuscular transmission, which was im- 
proved by neostigmine. These two effectsmyositis and neuromuscular blockage-appear to be independent of each other. Kalden, Williamson, Johnston, and Irvine (1969) immunized guinea-pigs with extracts of thymus tissue or skeletal muscle, together with Freund's adjuvant. This produced a 'thymitis', and a neuromuscular block, but no myositis. From the fact that neuromuscular transmission was unaffected in previously thymectomized animals they concluded that the block was directly or indirectly due to the 'thymitis'.

In our two cases, the clinical picture differs from the usual picture of myasthenia gravis only in its severity, and in the consequent need for drastic measures of treatment, including glossectomy, very high doses of neostigmine, and repeated courses of ACTH. We have considered the possibility that some of the more bizarre histological findings may be due, not to the natural progress of the disease, but in part at least to medication. This possibility cannot at present be excluded; but we would point out that the 'myasthenic tongue' was described by Buzzard in 1905, long before the days of anticholinesterase therapy. In the absence of experimental evidence of similar changes induced by neostigmine or ACTH, we are content to regard our findings as the outcome of exceptionally severe myasthenia gravis. In both cases, there was a poor response to thymectomy. It has been suggested (British Medical Journal, 1971) that in such cases a poor response may be due to permanent 'myositic' damage occurring before thymectomy. This does not seem to apply in our case 2, where myositic changes were slight, and almost confined to the bulbar musculature. It is also possible that a poor response may be due to incomplete thymectomy. It is difficult to be sure that removal has been complete, even at necropsy. No remnants of thymus were found in case 2 .

We do not propose to discuss the basic pathology of myasthenia gravis, which has recently been reviewed by Simpson (1969). Whatever the noxious agents may be, there are at least three 'target' structures; the thymus, skeletal muscle fibres, and neuromuscular junctions. The nature of the attack on muscle fibres is variable and probably non-specific, having features in common with a variety of toxic and autoimmune conditions. The disorder of the neuromuscular junction has been extensively studied by physiological, pharmacological, and ultrastructural techniques, with conflicting results. Structural abnormalities in motor nerve endings have repeatedly been demonstrated histologically, and a recent report (Edwards, 1970) claims that there are consistent changes in the ultrastructure of myasthenic end-plates-in particular, reduction in area of the post-synaptic membrane, and an increased space between this membrane and the terminal expansion of the nerve fibre; but there remains a large gap between histological and electron microscopical observations.

A simple hypothesis to explain our own observations and those of others is as follows. A hitherto unidentified agent (possibly a secretion of the thymus) alters the structure of the motor end-plate, rendering transmission of the nervous impulse more difficult. This partial functional denervation has the effect of stimulating motor nerve terminals to sprout and attempt the formation of fresh neuromuscular junctions (a similar stimulus exists when some motor nerve fibres degenerate, while others remain intact: Wohlfart, 1957, 1958). The new junctions are as ineffective as the old ones, and sprouting continues; meanwhile, the myotrophic function at these defective endings is maintained. At a later stage this too is lost, either at isolated neuromuscular junctions or in small groups, and the muscle fibres undergo irreversible 'neurogenic' atrophy. This increases the stimulus to sprouting of nerve fibres, but their terminations are no longer able to induce even a semblance of a subneural apparatus in the atrophic muscle fibres. This admittedly crude account dispenses with the need to suppose that there is a primary defect in motor neurones-a defect for which, at present, there is no direct evidence.

We are indebted to Dr. Geoffrey Rushworth for the electromyographic findings; to Mr. Ronald Beesley for the histological preparations; and to $\mathrm{Mr}$. Banham and Mr. David Luckett for photographic work.

\section{REFERENCES}

Bickerstaff, E. R., and Woolf, A. L. (1960). The intramuscular nerve endings in myasthenia gravis. Brain, 83, 10-23.

British Medical Journal (1971). Unsigned editorial: Pathogenesis of myasthenia gravis. British Medical Journal, 2, 1-2. Brody, I. A., and Engel, W. K. (1964). Denervation of muscle in myasthenia gravis. Archives of Neurology, 11, 350-354. 
Buzzard, E. F. (1905). The clinical history and post-mortem examination of five cases of myasthenia gravis. Brain, 28, 438-483.

Coërs, C., and Desmedt, J. E. (1958). Abnormal end-plates in myasthenic muscle. Lancet, ii, 1124.

Coërs, C. and Woolf, A. L. (1959). The Innervation of Muscle. A Biopsy Study. Blackwell: Oxford.

Desmedt, J. E. (1966). Presynaptic mechanisms in myasthenia gravis. Annals of the New York Academy of Sciences, 135, 209-246.

Edwards, W. (1970). Ultrastructural changes in the human motor endplate in myasthenia gravis. In VIth International Congress of Neuropathology. Proceedings. Paris, 1970, pp. 751-752. Masson: Paris.

Elmqvist, D., Hofmann, W. W., Kugelberg, J., and Quastel, D. M. J. (1964). An electrophysiological investigation of neuromuscular transmission in myasthenia gravis. Journal of Physiology, 174, 417-434.

Fenichel, G. M. (1966). Muscle lesions in myasthenia gravis. Annals of the New York Academy of Science, 135, 60-67.

Fenichel, G. M., and Shy, G. M. (1963). Muscle biopsy experience in myasthenia gravis. Archives of Neurology, 9, 237-243.

Goldstein, G. (1968). The thymus and neuromuscular function. Lancet, ii, 119-122.

Guth, L. (1968). 'Trophic' influences of nerve on muscle. Physiological Reviews, 48, 645-687.

Gutmann, E. (1964). Neurotrophic relations in the regeneration process. In Mechanisms of Neural Regeneration (Progress in Brain Research, vol. 13), pp. 72-114. Edited by M. Singer and J. P. Schadé. New York, Elsevier: Amsterdam.

Hughes, J. T., and Brownell, B. (1968). In Recent Advances in Clinical Pathology, series 5, p. 361. General editor S. C. Dyke. Churchill: London.
Kalden, J. R., Williamson, W. G., Johnston, R. J., and $\stackrel{\mathbb{\perp}}{\subseteq}$ Irvine, W. J. (1969). Studies on experimental autoimmune thymitis in guinea-pigs. Clinical and Experimental Immunology, 5, 319-340.

McComas, A. J., Sica, R. E. P., and Brown, J. C. (1971). Myasthenia gravis: evidence for a 'central' defect. Journal of the Neurological Sciences, 13, 107-113.

McComas, A. J., Sica, R. E. P., and Campbell, M. J. (1971). 'Sick' motoneurones. A unifying concept of muscle disease. 7 Lancet, i, 321-325.

MacDermot, V. (1960). The changes in the motor end-plate in myasthenia gravis. Brain, 83, 24-36.

Oppenheimer, D. R., Palmer, E., and Weddell, G. (1958). Nerve endings in the conjunctiva. Journal of Anatomy, 92, 321-352.

Russell, D. S. (1953). Histological changes in the striped $\stackrel{?}{+}$ muscles in myasthenia gravis. Journal of Pathology and Bacteriology, 65, 279-289.

Simpson, J. A. (1969). Myasthenia gravis and myasthenic $\overline{\bar{C}}$ syndromes. In Disorders of Voluntary Muscle, 2nd edn, $\vec{\nabla}$ pp. 541-578. Edited by J. N. Walton. Churchill: London. 요

Smith, A. C., Spalding, J. M. K., Ardran, G. M., and o Livingstone, G. (1965). Laryngectomy in the management $\mathrm{O}$ of severe dysphagia in non-malignant conditions. Lancet, $\vec{O}$ ii, 1094-1096.

Steidl, R. M., Oswald, A. J., and Kottke, F. J. (1962). Myasthenic syndrome with associated neuropathy. Archives of Neurology, 6, 451-461.

Wilson, S. A. K. (1955). Neurology, vol. 3, 2nd edition, p. 1730. Edited by A. N. Bruce. Butterworth: London.

Wohlfart, G. (1957). Collateral regeneration from residual motor nerve fibres in amyotrophic lateral sclerosi刃 $\omega$ Neurology (Minneap.), 7, 124-134.

Wohlfart, G. (1958). Collateral regeneration in partial $\vec{B}$ denervated muscles. Neurology (Minneap.), 8, 175-180. 